\title{
EFFECT OF CURING STRESS AND PERIOD ON THE MECHANICAL PROPERTIES OF CEMENT-MIXED SAND
}

\author{
Abu Taher Md Zillur Rabbi ${ }^{i}$, Jiro Kuwano ${ }^{\text {ii) }}$, Janliang Deng ${ }^{\text {iii) }}$ and Tay Wee Boon ${ }^{\text {iv) }}$
}

\begin{abstract}
Cement mixing is one of the popular ground improvement technologies in geotechnical engineering practice. In order to effectively and confidently design cement-mixed soil structures for specific purposes, its stress-strain behavior needs to be well understood. Though there have been many studies on cement-mixed soils using different types of soils, their behaviors have not been generalized yet. As is the case with concrete materials, the hydration of cement in cement-mixed soil continues with time, thereby improving the strength and deformation characteristics of cement-mixed soil over time. In the field, the cementation bonds are formed under stress in case of in-situ soil. However, in the usual testing techniques, cementation bonds under stress has not been a point of consideration in most of the previous studies. This has led to an underestimation of the stress-strain behavior of cement-mixed soil. On the other hand, soils are subjected to confining stress during loading which has also some effect on the strength and deformation characteristics of soil which has not been considered yet in the case of cement-mixed sand. This study investigates the effect of curing stress and period on the strength and deformation characteristics of cement-mixed sand. The effect of confining stress in the triaxial test is also investigated in another series of specimens. A series of consolidated drained (CD) triaxial compression (TC) tests were done along with the small strain cyclic loading and bender element tests during monotonic loading to determine the small strain Young's modulus $\left(E_{\mathrm{v}}\right)$ and shear modulus $\left(G_{\mathrm{vh}}\right)$ respectively. The effect of the curing period is significant in the peak strength, stiffness, $E_{\mathrm{v}}, G_{\mathrm{vh}}$ and also in the post peak regime. The curing stress also has a significant effect on the peak strength, $E_{\mathrm{v}}$ and $G_{\mathrm{vh}}$. The confining stress has an effect on the peak strength, stiffness and in the post peak regime. However, the effect is small compared to clean sand.
\end{abstract}

Key words: bender element test, cement-mixed sand, curing stress, phase transformation, triaxial test (IGC: D6/M5)

\section{INTRODUCTION}

Cement-mixed soil is a product of soil mixed with a relatively small amount of cement powder and properly designated quantity of water, which is expected to improve sustainability, and strength and the deformation characteristics of untreated soil. In recent years, it is widely used in ground improvement projects such as the reinforced soil wall in the bridge abutment backfill on the bullet train line in Kyushu, Japan (Kongsukprasert et al., 2005) and in highway embankments in Japan. A schematic illustration of the reinforced soil wall used in the Utsunomiya flyover bridge project is shown in Fig. 1. The use of cement-mixed soil is found to be relatively simple and economical compared to deep piling and the use of reinforced concrete structures since less concrete is required.

In order to effectively and confidently design cement- mixed soil structures for specific purposes, its stressstrain behavior needs to be well understood. Though there have been many studies on cement-mixed soil using different types of soils (Consoli et al., 2000, 2007; Tay W. B., 2005; Kongsukprasert et al., 2007), the behavior has yet to be generalized. Moreover, with the use of different testing techniques, there are discrepancies in the test results.

Hydration of cement in cement-mixed soil continues over a very long period (Kongsukprasert et al., 2007) which strengthens the cementation bonds between the particles and therefore more resistance to shearing. On the other hand, the cementation bonds in in situ soil are formed under stress. However, in the usual testing techniques, cementation bonds under stress have not been given the attention they should have been given. As a result, the stress-strain behavior of cement-mixed soil has been under-estimated (Consoli et al., 2000; Taguchi et

i) Assistant Professor, Department of Civil Engineering, Dhaka University of Engineering and Technology, Bangladesh (sumonbitr@ yahoo.com).

ii) Professor, Geosphere Research Institute, Graduate School of Science and Engineering, Saitama University, Japan (jkuwano@mail.saitamau.ac.jp).

iii) Post-Doctoral Fellow, ditto (dengjianliang@gmail.com).

iv) Singapore Government, Singapore (ta437@hotmail.com).

The manuscript for this paper was received for review on July 7, 2010; approved on March 8, 2011.

Written discussions on this paper should be submitted before May 1, 2012 to the Japanese Geotechnical Society, 4-38-2, Sengoku, Bunkyo-ku, Tokyo 112-0011, Japan. Upon request the closing date may be extended one month. 
al., 2002). Moreover, soils are subjected to different confining stresses at different ground depths, which may affect the strength and deformation characteristics of the soil during loading. However, the effect of confining stress has been given very little considerationin the case of cement-mixed sand.

The objective of this study is to investigate the coupled effect of curing stress and period on the strength and deformation characteristics of cement-mixed sand. To determine the effect of confining stress in triaxial tests on the mechanical properties of cemented sand cured in the absence of stress and under stress is another objective of this study.

\section{SPECIMEN AND METHODOLOGY}

\section{Specimen}

The amount of high-early-strength Portland cement used is $60 \mathrm{~kg}$ per $1 \mathrm{~m}^{3}$ of Toyoura sand, to achieve an unconfined compressive strength of $400-500 \mathrm{kPa}$ after 7 days of curing which is typical in a method used for the highway embankment introduced in Fig. 1. The component ratio is calculated such that the wet density of cement-mixed sand $\rho_{\mathrm{t}}=1.6 \mathrm{~g} / \mathrm{cm}^{3}$. Wet density is the moist density of the specimen just after preparing the sample: i.e., the moist density of specimen before curing. It is the ratio of the total mass of cement, sand and water to the total volume of the specimen. The properties and the ratios of the raw materials used in cement-mixed sand are shown in Table 1. The composition of cement-mixed sand used in this study is the same as that used in the

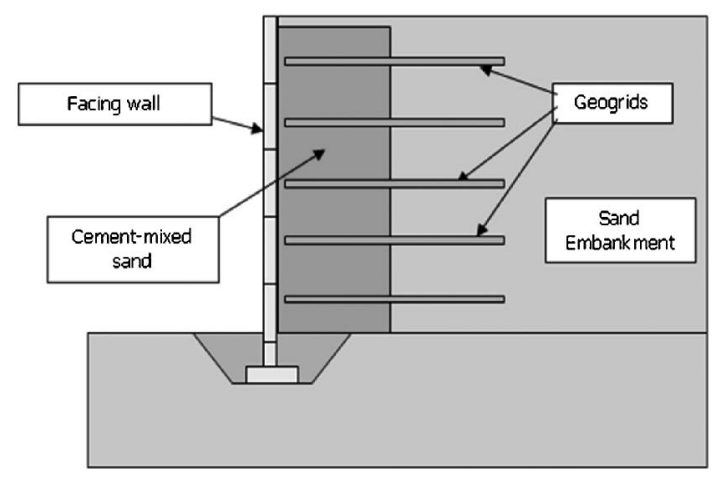

Fig. 1. Example of use of cement-mixed sand for reinforced soil wall

Table 1. Properties and ratio of raw materials

\begin{tabular}{|c|c|c|c|c|c|}
\hline & & & & \multicolumn{2}{|c|}{ Specific gravity, $G_{\mathrm{s}}$} \\
\hline \multicolumn{4}{|c|}{ Toyoura sand (S) } & \multicolumn{2}{|c|}{2.645} \\
\hline \multicolumn{4}{|c|}{ High-early-strength Portland cement (C) } & \multicolumn{2}{|c|}{3.130} \\
\hline \multirow[t]{2}{*}{ Water (W) } & & & & \multicolumn{2}{|c|}{1.000} \\
\hline & $S$ & $C$ & $W$ & $C / S$ & $W / C$ \\
\hline Ratio (\%) & 87.62 & 3.62 & 8.76 & 4.13 & 242 \\
\hline
\end{tabular}

study of cement-mixed sand by Kuwano and Tay (2007).

As noted, the amount of cement used is only $4.13 \%$ of the total weight of sand. This is small compared to normal cement mortar $(C / S=50 \%)$. Moreover, the watercement ratio used is about $242 \%$, which is higher compared to $W / C<100 \%$ for cement mortar. This amount of water was used to spread out the small amount of cement and ensure that the hydration of cement occurs throughout the specimen.

Specimens were cured for 3 different curing periods of 7, 28 and 90 days in order to study the effect of curing period on the stress-strain characteristics of cement-mixed sand. For each curing period, specimens were cured under 2 different curing stresses, $\sigma_{\mathrm{v}}$ of $0 \mathrm{kPa}$ and $98 \mathrm{kPa}$, to investigate the effect of stress during the formation of cementation bonds.

In another series, 7 and 28 days specimens were cured without any stress and under stresses $(0 \mathrm{kPa}$ and $98 \mathrm{kPa})$, and each specimen was sheared under 3 different effective confining stresses, 98, 147 and $196 \mathrm{kPa}$, to investigate the effect of confining stress in triaxial test. To compare the test results of the cement-mixed sand, the specimen pre-

Table 2. Test cases to study effect of curing stress and period (Series 1)

\begin{tabular}{lccc}
\hline \multirow{2}{*}{$\begin{array}{c}\text { Specimen } \\
\text { type }\end{array}$} & $\begin{array}{c}\text { Curing } \\
\text { overburden } \\
\text { stress }\end{array}$ & $\begin{array}{c}\text { Curing time } \\
\text { (days) }\end{array}$ & $\begin{array}{c}\text { Effective } \\
\text { confining } \\
\text { stress (kPa) }\end{array}$ \\
\hline & $0 \mathrm{kPa}$ & 7 & 98 \\
\cline { 3 - 4 } $\begin{array}{l}\text { Cement- } \\
\text { mixed sand }\end{array}$ & $98 \mathrm{kPa}$ & 28 & 98 \\
\cline { 3 - 4 } & & 70 & 98 \\
\cline { 3 - 4 } & - & 90 & 98 \\
\hline Clean sand & - & - & 98 \\
\hline
\end{tabular}

Table 3. Test cases to study effect of confining stress (Series 2)

\begin{tabular}{|c|c|c|}
\hline $\begin{array}{c}\text { Curing overburden } \\
\text { stress }\end{array}$ & $\begin{array}{l}\text { Curing time } \\
\text { (days) }\end{array}$ & $\begin{array}{l}\text { Effective confining } \\
\text { stress }(\mathrm{kPa})\end{array}$ \\
\hline \multirow{6}{*}{$0 \mathrm{kPa}$} & 7 & 98 \\
\hline & 7 & 147 \\
\hline & 7 & 196 \\
\hline & 28 & 98 \\
\hline & 28 & 147 \\
\hline & 28 & 196 \\
\hline \multirow{6}{*}{$98 \mathrm{kPa}$} & 7 & 98 \\
\hline & 7 & 147 \\
\hline & 7 & 196 \\
\hline & 28 & 98 \\
\hline & 28 & 147 \\
\hline & 28 & 196 \\
\hline
\end{tabular}


pared with untreated Toyoura sand was tested in a triaxial compression testing machine. The specimen with clean Toyoura sand was prepared by pouring sand from a funnel with a constant falling height to control uniform density all through the specimen height. The density of the specimen prepared with clean sand was $1.54 \mathrm{~g} / \mathrm{cm}^{3}$. All the test cases are shown in Table 2 and Table 3.

Sand and cement were mixed thoroughly together and then water was added to the mixture and they were mixed thoroughly again. The mixture was then compacted into moulds of height $150 \mathrm{~mm}$ and diameter $75 \mathrm{~mm}$ to control the wet density of the specimen $1.6 \mathrm{~g} / \mathrm{cm}^{3}$. Compaction was done in 5 stages of about the same amount of cement-mixed sand each time. For ease of compaction, the top layer was compacted using an additional $30 \mathrm{~mm}$ height of the mould, which can be separated into parts. The specimens were then stored under constant temperature of $20^{\circ} \mathrm{C}$ and humidity of $50 \%$ for the specified number of days before they were used for experimental pur-

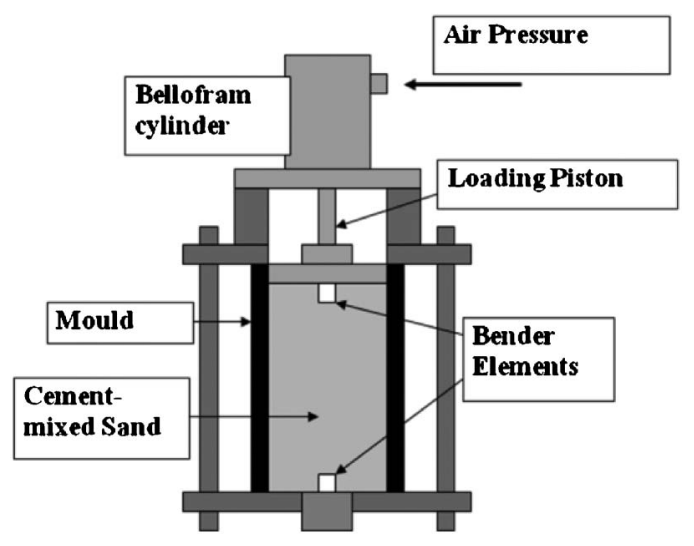

Fig. 2. Consolidation mould for applying curing stress with BE monitoring poses. Specimens to be cured with stress were set in a specially made consolidation apparatus as shown in Fig. 2. The specimens were then loaded with the desired amount of overburden stress immediately after the moulds were filled. The loading was applied using air pressure in the bellofram cylinder mounted on that special apparatus. The change in shear modulus during curing with stress was monitored using a pair of bender elements attached at the top and bottom ends of the specially made consolidation apparatus as shown in Fig. 2.

\section{Triaxial Test Apparatus}

The triaxial compression test system used in this study consists of 2 main parts, triaxial test and bender element test. In triaxial test, output voltages from all measuring sensors are converted into digital signals which were recorded on the $\mathrm{PC}$ through a 16-bit $\mathrm{AD}$ converter. In turn, the control signals from the $\mathrm{PC}$ are converted into voltages for each control sensor, through a 12-bit DA converter as shown schematically in Fig. 3 (Chaudhary et al., 2004). The local strain was estimated for the Young's modulus from the measurement of the LDT as shown in Fig. 3 as the LDT has a lower electrical noise level. Since, however, the measuring range of the LDT is only $2.5 \%$, the measurements of inner LVDT are used as a supplement to the LDT beyond the range of $2.5 \%$. The measuring range of the inner LVDT was $15 \%$.

In the bender element test, a function generator sends out a sine pulse wave, as proposed by Viggani and Atkinson (1995), to the transmitter at one end of the specimen. The receiver at the other end of the specimen receives this wave. Both wave patterns at the transmitter and receiver ends are outputted into an oscilloscope screen. The time taken for sine pulse wave to pass through the specimen is the time lapse between the start of transmitting wave and the start of the receiving wave pattern, as shown in Fig. 4.

Figure 5 shows the arrangement of bender elements

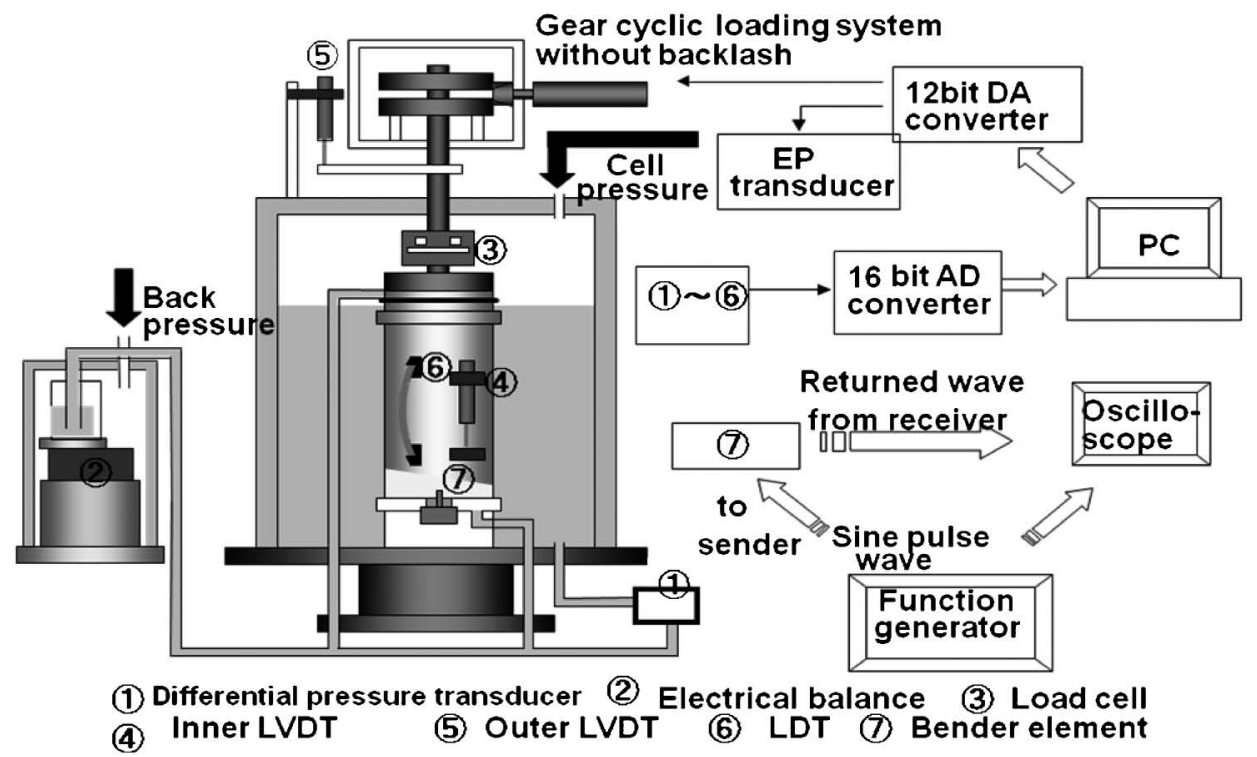

Fig. 3. Schematic illustration of triaxial system (not in scale); Specimen dimensions: $h=150 \mathrm{~mm}, d=75 \mathrm{~mm}(\mathrm{Chaudhary}$ et al., 2004$)$ 


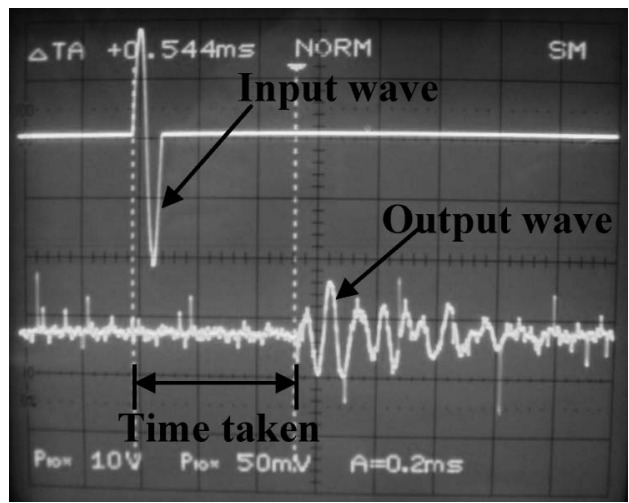

Fig. 4. Measurement of time taken by shear wave to pass through the specimen

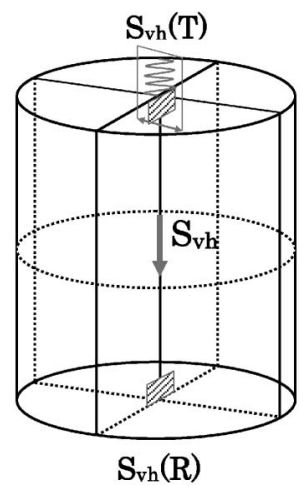

Fig. 5. Arrangement of bender elements

used in this experiment. The transmitting and receiving ends are denoted by $(\mathrm{T})$ and $(\mathrm{R})$ respectively. The shear wave is denoted by $S_{\mathrm{vh}}, v$ refers to the direction of propagation and $h$ refers to the direction of motion of soil particles. The distance traveled by the shear wave is taken as the distance between the tips of the transmitter and receiver bender elements, proposed by Dyvik and Madshus (1985).

The shear modulus is then calculated using the following equation:

$$
G=\rho V^{2}
$$

$\rho$ : Density of specimen

$V$ : Shear wave velocity

\section{Experimental Conditions}

Specimens were taken out of their moulds after their respective curing days and saturated with de-aired water in the triaxial cell. Backpressure and cell pressure were then applied up to $200 \mathrm{kPa}$ and $225 \mathrm{kPa}$ respectively, while the effective confining stress was kept constant at 25 $\mathrm{kPa}$. For Series 1, the specimens were then isotropically consolidated to an effective confining stress of $98 \mathrm{kPa}$, after that, drained monotonic loading was applied. For Series 2, the specimens were isotropically consolidated to their respective confining stresses i.e., 98, 147 and 196 $\mathrm{kPa}$. After that, drained monotonic loading was applied

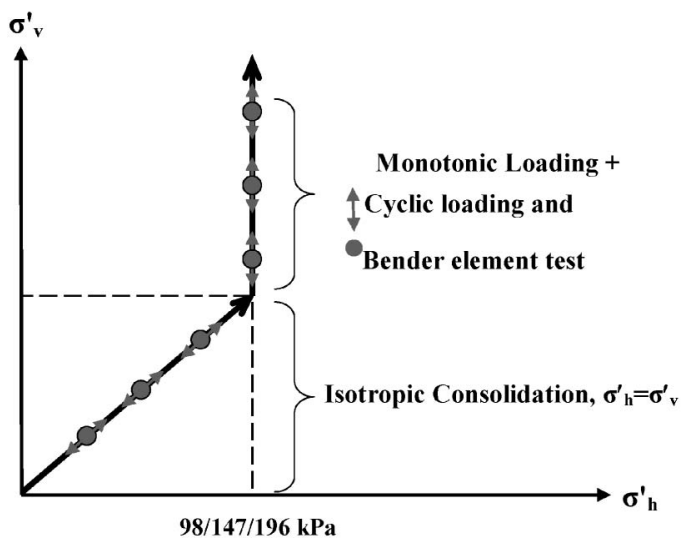

Fig. 6. Stess path for all the tests

as it was to Series 1 . In case of specimen prepared with clean Toyoura sand, the specimen was isotropically consolidated to an effective confining stress of $98 \mathrm{kPa}$, and then drained monotonic loading was applied. The stress path for all the test cases is shown in Fig. 6. The effective vertical and horizontal stress are denoted by $\sigma_{\mathrm{v}}^{\prime}$ and $\sigma_{\mathrm{h}}^{\prime}$, respectively.

In all test cases, the loading strain rate was kept constant at $0.01 \% / \mathrm{min}$. Cyclic loading at an amplitude of $\pm 4 \mathrm{kPa}$ to produce small strains of about $10^{-5} \sim 10^{-4}$ and the bender element test were carried out at intervals to obtain the change in the Young's modulus and the shear modulus during shear loading. Properties of specimens are as shown in Table 4.

\section{EFFECT OF CURING STRESS AND PERIOD (SERIES 1)}

\section{Consolidation and Drained Monotonic Loading}

Figure 7 shows the stress-strain relationships for specimens cured without and under stress. It can be observed that the deviator stress $q$ increases with the axial strain $\varepsilon_{\mathrm{v}}$, reaches to peak and then reduces gradually. This brittle behavior in the post peak region is more prominent in case of specimens cured for longer periods of time. The cementation bonds result in changes in the cement-mixed Toyoura sand from a ductile to stiff brittle material, its strength increases by a factor of approximately 3.5 over 90 days. The stiffness of specimens increases with curing time regardless of the availability of acting stresses during curing. On the other hand, specimens cured under stress are noted to be slightly stiffer than those cured in the absence of stress, as shown in Fig. 7. This could be explained by the coupled effect of the specimen becoming denser upon loading during the initial curing stage and the hydration process of the cement.

Figure 8 shows that the peak strength $q_{\max }$ increases with curing time regardless of the availability of acting stresses during curing. Specimens cured under stress are noted to have higher peak strength during shearing than those cured in the absence of stress. The rate of increase in peak strength with curing period for specimens cured 
Table 4. Properties of specimen

\begin{tabular}{|c|c|c|c|c|c|c|}
\hline & \multirow{2}{*}{$\begin{array}{l}\text { Curing period } \\
\text { (days) }\end{array}$} & \multirow{2}{*}{$\begin{array}{l}\text { Curing stress } \\
(\mathrm{kPa})\end{array}$} & \multirow{2}{*}{$\begin{array}{l}\text { Confining stress in } \\
\text { triaxial test }(\mathrm{kPa})\end{array}$} & \multicolumn{2}{|c|}{ Wet density, $\rho_{\mathrm{t}}\left(\mathrm{g} / \mathrm{cm}^{3}\right)$} & \multirow{2}{*}{$\begin{array}{l}\text { Void ratio, } e \\
\text { Before curing }\end{array}$} \\
\hline & & & & Before curing & After curing & \\
\hline \multirow{12}{*}{$\begin{array}{l}\text { Cement-mixed } \\
\text { sand }\end{array}$} & \multirow{5}{*}{7} & \multirow{3}{*}{0} & 98 & 1.641 & 1.625 & 0.7772 \\
\hline & & & 147 & 1.637 & 1.621 & 0.7813 \\
\hline & & & 196 & 1.635 & 1.619 & 0.7836 \\
\hline & & \multirow[t]{2}{*}{98} & 147 & 1.636 & 1.633 & 0.783 \\
\hline & & & 196 & 1.644 & 1.636 & 0.7732 \\
\hline & \multirow{5}{*}{28} & \multirow[b]{2}{*}{0} & 98 & 1.616 & 1.620 & 0.8046 \\
\hline & & & 147 & 1.607 & 1.611 & 0.8151 \\
\hline & & \multirow{3}{*}{98} & 98 & 1.636 & 1.645 & 0.7826 \\
\hline & & & 147 & 1.63 & 1.638 & 0.7879 \\
\hline & & & 196 & 1.631 & 1.639 & 0.7704 \\
\hline & \multirow{2}{*}{90} & 0 & 98 & 1.631 & 1.640 & 0.7879 \\
\hline & & 98 & 98 & 1.647 & 1.655 & 0.7704 \\
\hline \multicolumn{2}{|c|}{ Clean Toyoura sand } & - & 98 & 1.54 & - & 0.7176 \\
\hline
\end{tabular}

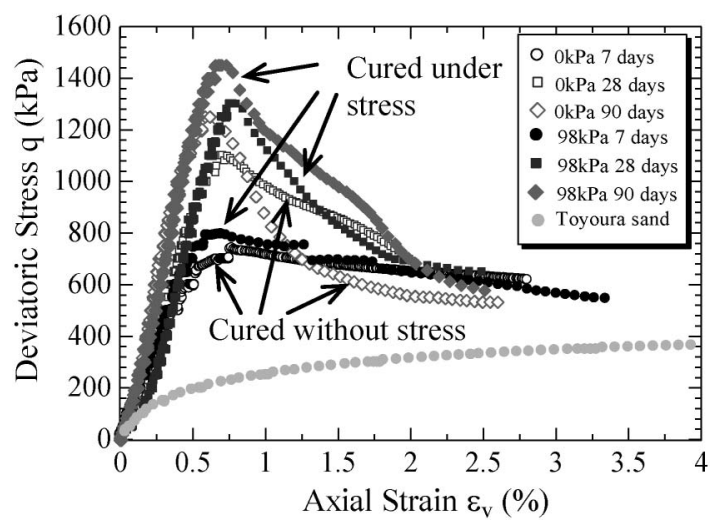

Fig. 7. Stress-strain relationship for specimens cured without and under stress (Series 1)

without any stress and under stress can be expressed by the following Eqs. (2) and (3) respectively, which are obtained directly from Fig. 8 .

$$
q_{\max }=380+460 \log T
$$

[For specimens cured in the absence of stress]

and

$$
q_{\max }=338+596 \log T
$$

[For specimens cured under stress] where, $q_{\max }=$ Peak strength in $\mathrm{kPa}$ and $T=$ Curing period in days.

These two equations show that the rate of increase in peak strength is higher for the specimen cured under stress especially in the early stage of curing. This again shows that the acting stresses during curing enhance the

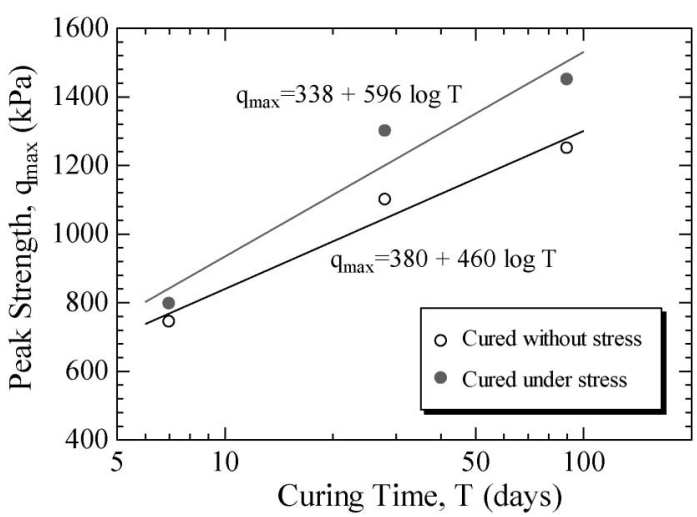

Fig. 8. Change of peak strength with time (Series 1)

formation of the cementation bonds and thus improve the specimen's resistance to shearing. Figure 9 shows the relationship between volumetric strain and axial strain during shearing for specimens cured in the absence of stress and under stress. Here, the positive and negative value of the volumetric strain indicates the dilative and contractive behavior respectively. It is observed that specimens become less compressive and more dilatant with longer curing times.

As expected, specimens cured under stress are more dilatant than those cured without stress. However, the reverse is seen in specimens cured for 28 days and also after $1.25 \%$ of axial strain for 90 days specimens. The concentration of strain at the slip surface may result in the concentration of the volume change around the slip surface, making the specimen as a whole less dilatant. 


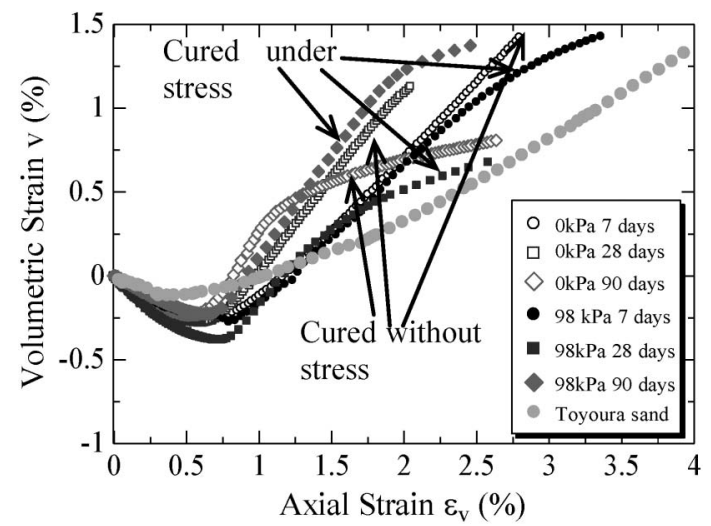

Fig. 9. Volumetric strain curve for specimens cured in the absence of stress and under stress (Series 1)

\section{Cyclic Loading Test}

Young's modulus $E_{\mathrm{v}}$ is dependent on the loading stress $\sigma_{\mathrm{v}}^{\prime}$ and the void ratio $e$ of specimen. The following equation can be used to represent $E_{\mathrm{v}}$ (e.g., Hardin and Blandford, 1989; Chaudhary et al., 2004):

$$
\frac{E_{\mathrm{v}}}{p_{\mathrm{r}}}=C_{\mathrm{v}} F(e)\left(\frac{\sigma_{\mathrm{h}}^{\prime}}{p_{\mathrm{r}}}\right)^{\mathrm{n}_{\mathrm{h}}}\left(\frac{\sigma_{\mathrm{v}}^{\prime}}{p_{\mathrm{r}}}\right)^{\mathrm{n}_{\mathrm{v}}}
$$

where

$$
F(e)=\frac{(2.17-e)^{2}}{(1+e)}
$$

$C_{\mathrm{v}}, n_{\mathrm{h}}$ and $n_{\mathrm{v}}$ are constants and can be obtained from experimental data, while $p_{\mathrm{r}}$ is the reference stress. In this study, the reference stress $p_{\mathrm{r}}$ is taken as $1 \mathrm{kPa}$. Since the void ratio, $e$ is almost same for all the specimens, $F(e)$ is constant for all specimens. Also, since the effective confining stress, $\sigma_{\mathrm{h}}^{\prime}$ is constant for all the specimens, Eq. (4) can be expressed in the form $E_{\mathrm{v}}=A\left(\sigma_{\mathrm{v}}^{\prime}\right)^{\mathrm{n}}$, where $A$ and $n$ are constants. This is a straight line when $E_{\mathrm{v}}$ and $\sigma_{\mathrm{v}}^{\prime}$ are plotted in logarithmic scale. Therefore, $E_{\mathrm{v}}$ is plotted against vertical effective confining stress, $\sigma_{\mathrm{v}}^{\prime}$ in a logarithmic scale, as shown in Fig. 10.

Figure 10 shows the change in $E_{\mathrm{v}}$ during the monotonic loading for specimens cured in the absence of stress and under stress. It can be observed that $E_{\mathrm{v}}$ increases with $\sigma_{\mathrm{v}}^{\prime}$ and follows Eq. (4). $E_{\mathrm{v}}$ drops when vertical effective stress $\sigma_{\mathrm{v}}^{\prime}$ is about $45 \%$ to $60 \%$ of its peak value. This may be explained as follows: $E_{\mathrm{v}}$ increases when specimens become stiffer with increases in the vertical contact forces between the sand particles during monotonic loading, but it decreases when the cementation bonds start to break down.

It is found that the Young's modulus increases notably with the curing period, regardless of the availability of curing stress. Also, it is quite apparent that specimens cured under stress have a higher Young's modulus, regardless of the number of curing days. The rate of increase of $E_{\mathrm{v}}$ with $\sigma_{\mathrm{v}}^{\prime}$, however, is higher for specimens cured in the absence of stress. This shows that specimens cured without stress are more compressive.

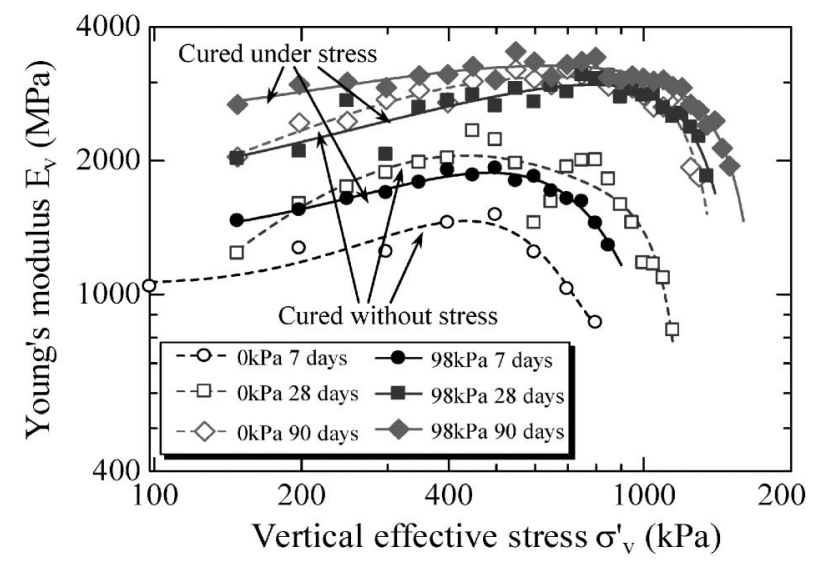

Fig. 10. Change of Young's modulus for specimens cured in the absence of stress and under stress (Series 1)

\section{Bender Element Test}

As is the case with the Young's modulus, the shear modulus, $G_{\mathrm{vh}}$ is dependent on the vertical effective stress $\sigma_{\mathrm{v}}^{\prime}$, the horizontal effective stress $\sigma_{\mathrm{h}}^{\prime}$ and the void ratio of specimen. The following equation can be used to represent $G_{\text {vh }}$ (e.g., Hardin and Blandford, 1989; Chaudhary et al., 2004):

$$
\frac{G_{\mathrm{vh}}}{p_{\mathrm{r}}}=C_{\mathrm{v}} F(e)\left(\frac{\sigma_{\mathrm{h}}^{\prime}}{p_{\mathrm{r}}}\right)^{\mathrm{n}_{\mathrm{h}}}\left(\frac{\sigma_{\mathrm{v}}^{\prime}}{p_{\mathrm{r}}}\right)^{\mathrm{n}_{\mathrm{v}}}
$$

All parameters here are the same as defined in Young's modulus. The effective confining stress, $\sigma_{\mathrm{h}}^{\prime}$ is also constant for all the specimens. Therefore, Eq. (5) can be rewritten as $G_{\mathrm{vh}}=B\left(\sigma_{\mathrm{v}}^{\prime}\right)^{\mathrm{m}}$, where $B$ and $m$ are constants. This is also a straight line when $G_{\mathrm{vh}}$ and $\sigma_{\mathrm{v}}^{\prime}$ are plotted on a logarithmic scale, as shown in Fig. 11.

\section{Change in $G_{\mathrm{vh}}$ during Curing}

Figure 12 shows the change in the shear modulus in the vertical plane $G_{\mathrm{vh}}$ and change in void ratio $e$ during the curing stage. As the void ratio decreases during the loading stage, $G_{\mathrm{vh}}$ increases; however, as time passes, $G_{\mathrm{vh}}$ continues to increase even when void ratio remains almost constant. This can be explained by the strengthening of the cementation bonds due to the hydration of cement. This is also true for specimens cured without stress (clear dots). This observation, i.e., the $G_{\mathrm{vh}}$ of specimen cured under stress is higher than that of cured without stress, again shows the coupled effect of loading during the initial curing stage and the hydration process of cement.

In the specimens cured in the absence of stress, $G_{v h}$ approaches the $G_{\mathrm{vh}}$ of the specimen cured under stress as time passes. Due to the time constraints of this study, whether or not the $G_{\mathrm{vh}}$ of the specimen cured in the absence of stress actually increases to the level of that cured under stress with time was not able to be observed.

\section{Change in $G_{\mathrm{vh}}$ during Shear Loading}

Figure 11 shows the change in the shear modulus $G_{\mathrm{vh}}$ with vertical effective stress $\sigma_{\mathrm{v}}^{\prime}$ in both isotropic consolidation and triaxial compression stages for specimens 


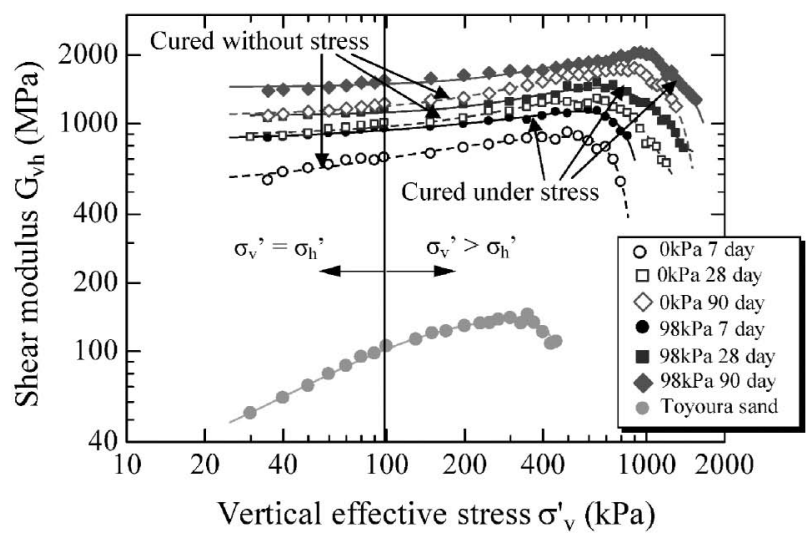

Fig. 11. Change of shear modulus for specimens cured in the absence of stress and under stress (Series 1)

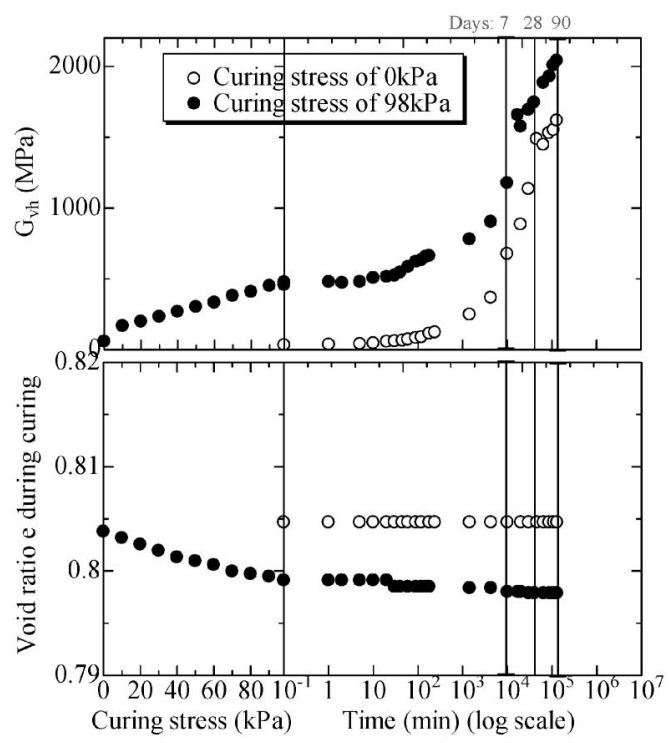

Fig. 12. Change in $G_{\mathrm{vh}}$ and void ratio during curing

cured in the absence of stress and under stress during shearing. For all the specimens, $G_{\mathrm{vh}}$ increases with the $n$ power of $\sigma_{v}^{\prime}$ which follows Eq. (5) and it drops when $\sigma_{v}^{\prime}$ reaches about $40 \%$ to $60 \%$ of its peak value. As the specimens become denser during monotonic loading, $G_{\mathrm{vh}}$ increases and then drop when the cementation bonds start to break. This is similar to what occurs in the case of the Young's modulus. The shear modulus $G_{\mathrm{vh}}$ of cement-mixed sand increases with time regardless of the availability of the curing stress, as is the case with the stiffness, peak strength and the Young's modulus. On the other hand, when compared to specimens cured in the absence of stress and under stress, it should be noted that the specimens cured under stress have a higher $G_{\mathrm{vh}}$ regardless of the curing period. It is also observed that the rate of increase of $G_{\mathrm{vh}}$ with $\sigma_{\mathrm{v}}^{\prime}$ is slightly higher for specimens cured without stress, which is also similar to what was found in the case of the Young's modulus.

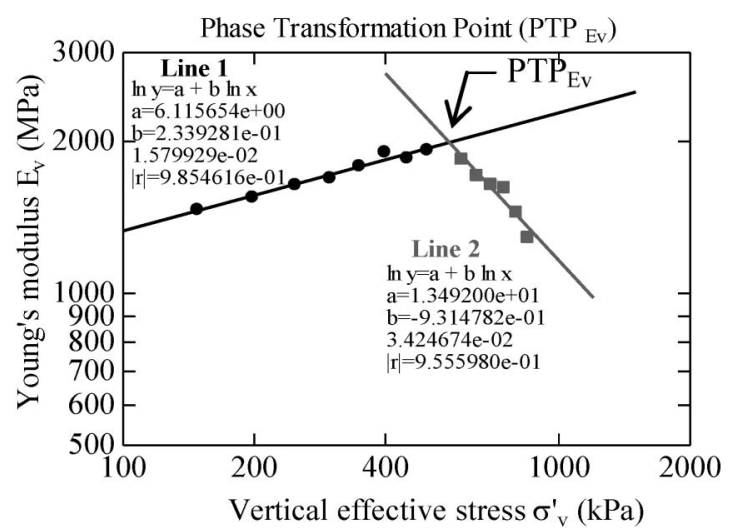

Fig. 13. Example of determination of phase trasnsformation points

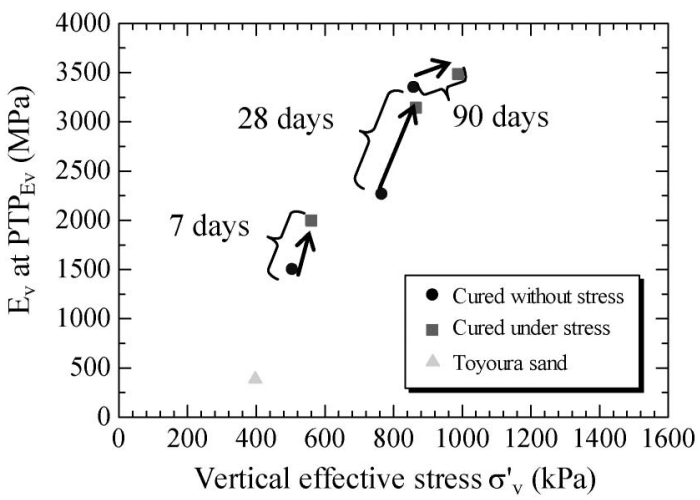

Fig. 14. Relationship of $\mathrm{PTP}_{\mathrm{Ev}}$ with $\sigma_{\mathrm{v}}^{\prime}$

\section{Phase Transformation Points}

For all the specimens, the Young's modulus $E_{\mathrm{v}}$ and shear modulus $G_{\mathrm{vh}}$ both increase with the increase in vertical effective confining stress $\sigma_{v}^{\prime}$ initially and at a certain level of $\sigma_{\mathrm{v}}^{\prime}$ they start decreasing. The points at which $E_{\mathrm{v}}$ and $G_{\mathrm{vh}}$ change from an increasing to a decreasing tendency are introduced here as phase the transformation points for the Young's modulus $\left(\mathrm{PTP}_{\mathrm{Ev}}\right)$ and the shear modulus $\left(\mathrm{PTP}_{\mathrm{Gvh}}\right)$, respectively. The phase transformation points for $E_{\mathrm{v}}$ and $G_{\mathrm{vh}}$ are determined by drawing two straight lines in the initial and final straight portion of the $E_{\mathrm{v}}-\sigma_{\mathrm{v}}^{\prime}$ and $G_{\mathrm{vh}}-\sigma_{\mathrm{v}}^{\prime}$ curves respectively when they are plotted in log-log scale, as shown in Figs. 10 and 11. The straight lines in the initial and final straight portion of the $E_{\mathrm{v}}-\sigma_{\mathrm{v}}^{\prime}$ and $G_{\mathrm{vh}}-\sigma_{\mathrm{v}}^{\prime}$ curves are obtained by drawing trend lines in the form of $E_{\mathrm{v}}=A\left(\sigma_{\mathrm{v}}^{\prime}\right)^{\mathrm{n}}$, and $G_{\mathrm{vh}}=B\left(\sigma_{\mathrm{v}}^{\prime}\right)^{\mathrm{m}}$ respectively, which are derived from Eqs. (4) and (5), respectively. The points where these two lines cross are the phase transformation points, as shown in Fig. 13 in case of $E_{\mathrm{v}}$. It can be observed from Figs. 14 and 15 that the curing stress and period both increases the range of $\sigma_{v}^{\prime}$ where $\mathrm{PTP}_{\mathrm{Ev}}$ and PTP $_{\text {Gvh }}$ occurs. Also, cementation results in much more significant increases in the $E_{\mathrm{v}}$ and $G_{\mathrm{vh}}$ values at the phase transformation points when compared with clean sand.

In Figs. 16 and 17 the phase transformation points for $E_{\mathrm{v}}\left(\mathrm{PTP}_{\mathrm{Ev}}\right), G_{\mathrm{vh}}\left(\mathrm{PTP}_{\mathrm{Gvh}}\right)$, volume change $\left(\mathrm{PTP}_{\mathrm{v}}\right)$ and peak strength $\left(q_{\max }\right)$ is plotted in the stress-strain field for 


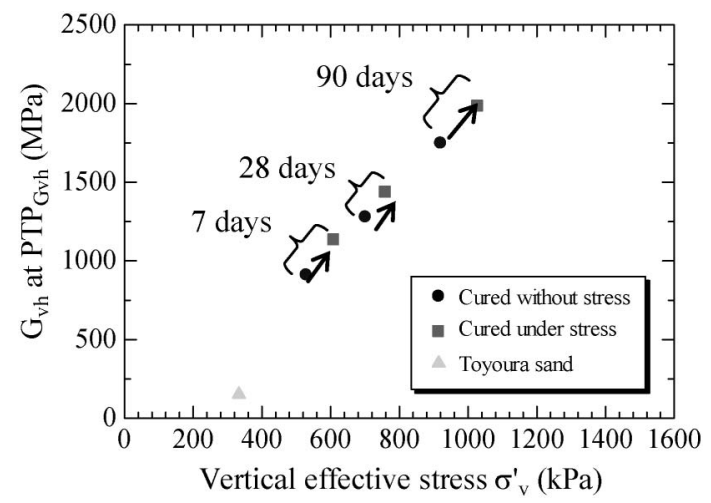

Fig. 15. Relationship of PTP $\mathbf{P v h}_{\text {with } \sigma_{v}^{\prime}}$

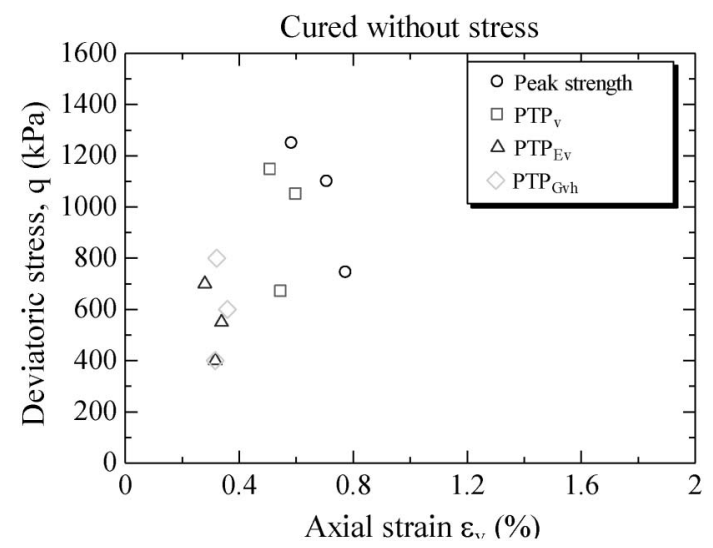

Fig. 16. Phase Transformation Points (PTP) plotted in stress-strain field for specimens cured in the absence of stress (Series 1)

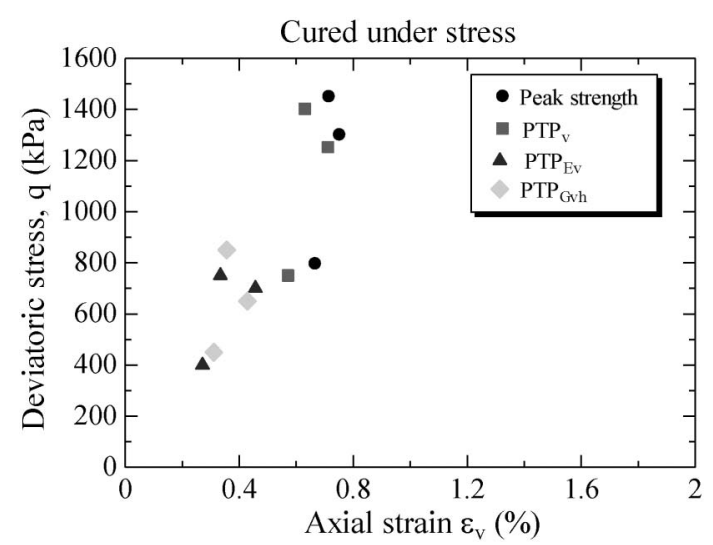

Fig. 17. Phase Transformation Points (PTP) plotted in stress-strain field for specimens cured under stress (Series 1)

specimens cured without and under stress respectively. With the increase in curing period, the deviator stress for the respective PTP states is higher. The phase transformation point for volume change is taken where the volumetric strain curve changes their phase from a compressive to a dilatant behavior. It can be observed that the $\mathrm{PTP}_{\mathrm{Ev}}$ and $\mathrm{PTP}_{\mathrm{Gvh}}$ were first obtained during the shear loading. Following that, the phase transformation points for the volume change $\mathrm{PTP}_{\mathrm{v}}$ and $q_{\max }$ are obtained. It can also be observed that $\mathrm{PTP}_{\mathrm{Ev}}$ and $\mathrm{PTP}_{\mathrm{Gvh}}$ are found at almost the same axial strain level irrespective of the curing stress and curing period before $\mathrm{PTP}_{\mathrm{v}}$ and $q_{\text {max }}$. This indicates that the degradation of the cementation bond starts after a certain level of axial deformation due to the relative displacement of the particles. The amount of relative displacement is sufficient to start the break down in the cementation bond, but this relative displacement level is not enough to cause the specimen to show dilatancy.

In the case of clean Toyoura sand, decreases in $E_{\mathrm{v}}$ and $G_{\mathrm{vh}}$ with shearing were also found, but this occurred after the phase transformation point for volume change, $\mathrm{PTP}_{\mathrm{v}}$ (Kuwano et al., 2005). The breakage of the cementation bond does not explain this decrease in the stiffness of clean sand. A DEM simulation of a biaxial compression test was carried out to study the change in the stiffness of clean sand (Ohba et al., 2001). In the DEM simulation, 3000 circle elements with a diameter of 1.5 to $2.5 \mathrm{~mm}$ were first consolidated isotropically up to $98 \mathrm{kPa}$. Then the specimen was sheared with the vertical compression at a strain rate of $1 \% / \mathrm{min}$ while the horizontal stress was kept constant $(98 \mathrm{kPa})$. According to the DEM simulation of the biaxial compression test, the force columns are formed in the specimen up to $\mathrm{PTP}_{\mathrm{v}}$. However, after $\mathrm{PTP}_{\mathrm{v}}$, there are fewer particles which transmit forces normal to the column, resulting in a decrease in the support of the column. This results in a fragile structure and decrease in the stiffness of the soil. In the case of cementmixed sand, a decrease in the stiffness observed in the laboratory tests appears before the $\mathrm{PTP}_{\mathrm{V}}$, indicating that the breakage of cementation bond occurs at relatively small strain levels and is a predominant factor in the reduction of stiffness of cement-mixed sand.

\section{EFFECT OF CONFINING STRESS (SERIES 2)}

\section{Consolidation and Drained Monotonic Loading}

Figures 18(a) and (b) show the stress-strain relationships under different confining stress conditions for specimens cured in the absence of stress and under stress, respectively. It is observed that the deviator stress $q$ increases with the axial strain $\varepsilon_{\mathrm{v}}$, reaches to peak and then reduces gradually. This tendency is similar to that observed in Series 1. However, this brittle behavior in the post peak region decreases with the increase in confining stress for specimens with the same curing period. The stiffness of the specimen also increases slightly with the increase in confining stress. Figure 19 shows the peak strength envelopes for different curing conditions. It is seen that peak strength increases with the increase in confining stress. This might be due to two reverse actions: firstly, specimens become denser due to higher confining stress and secondly, particle bonding might break during isotropic consolidation with higher effective confining stress. However, the rate of increase is much more gradual than that of clean sand. The dilatancy of specimens decreases with the increase in confining stress regardless of the curing stress and period, as shown by the volumet- 


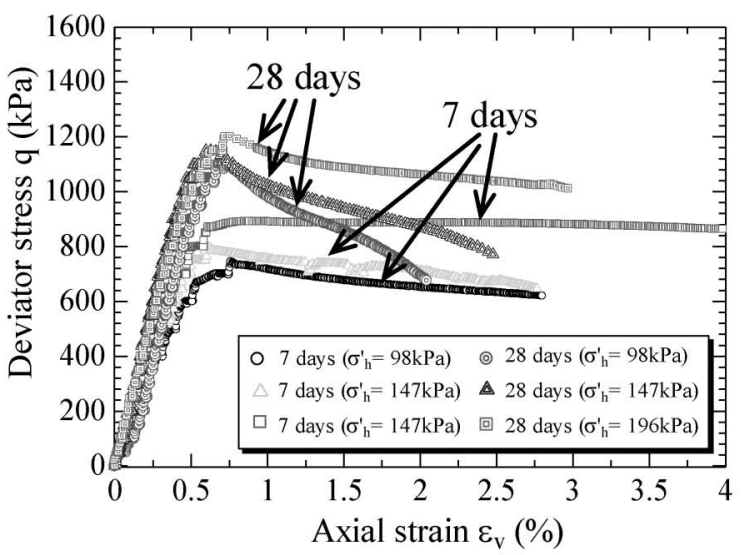

(a)

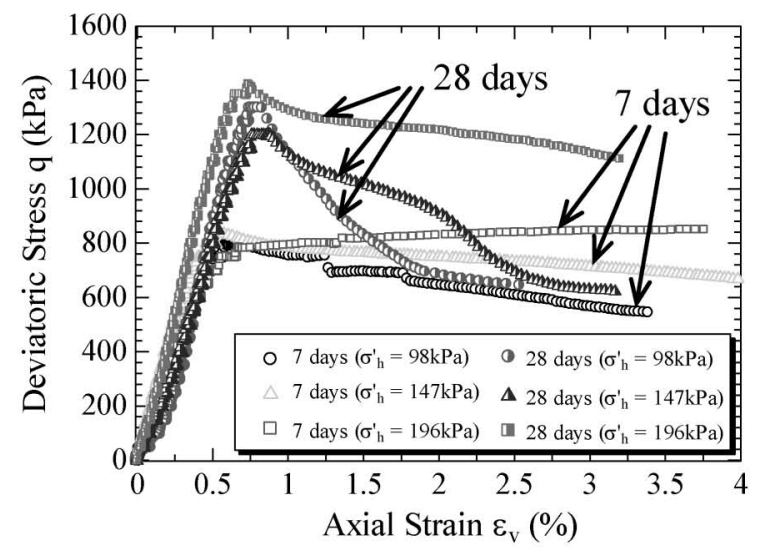

(b)

Fig. 18. Stress-strain relationship for specimens (a) cured in the absence of stress, (b) cured under stress (Series 2)

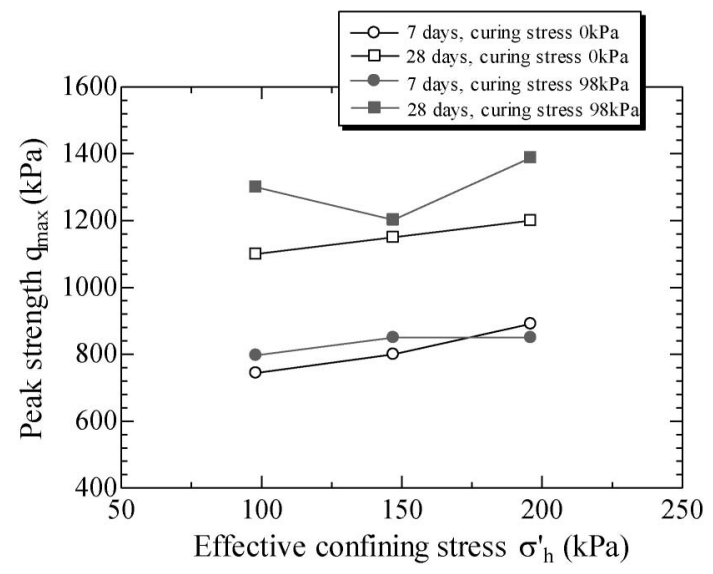

Fig. 19. Peak strength envelope for different curing conditions

ric strain curves in Figs. 20(a) and (b).

\section{Cyclic Loading Test}

Similar to Series 1, Young's modulus $E_{\mathrm{v}}$ is plotted against $\sigma_{v}^{\prime}$ in this series. Figures 21(a) and (b) show the change in $E_{\mathrm{v}}$ with $\sigma_{\mathrm{v}}^{\prime}$ under different confining stress conditions for specimens cured in the absence of stress and under stress, respectively. For all the specimens, $E_{\mathrm{v}}$ increases with the increase in vertical effective stress $\sigma_{\mathrm{v}}^{\prime}$ and drops when $\sigma_{\mathrm{v}}^{\prime}$ reaches $50 \%$ to $60 \%$ of its peak value. This tendency is similar to the results obtained in Series 1. However, the effect of confining stress on the Young's modulus is relatively small for both specimens cured in the absence of stress and under stress. Although $E_{\mathrm{v}}$ was expected to decrease at higher confining stress where the cementation bond is broken due to relative displacements at the particle contacts, this small range of confining stress might not able to break the cementation bond to decrease the $E_{\mathrm{v}}$ value.

\section{Bender Element Test}

Figures 22(a) and (b) show the change in the shear modulus $G_{\mathrm{vh}}$ for specimens cured without and under stress, respectively, under different confining stress conditions. As was the case with $E_{\mathrm{v}}$, the shear modulus $G_{\mathrm{vh}}$ also increases with vertical effective stress $\sigma_{\mathrm{v}}^{\prime}$ and drops when $\sigma_{\mathrm{v}}^{\prime}$ reaches about $50 \%$ to $60 \%$ of its peak value. A slight increase in $G_{\mathrm{vh}}$ is observed with increasing confining stress, regardless of the curing stress and period, but the effect is small. The effect of confining stress was less for all specimens cured under stress than specimens cured without any stress. This indicates that specimens cured under stress have higher cementation bonds than those cured in the absence of stress and, therefore, the change in the effective stress has less effect on the mechanical properties of cement-mixed sand.

\section{Phase Transformation Points}

As was the case with Series 1, the phase transformation points in this series, $E_{\mathrm{v}}\left(\mathrm{PTP}_{\mathrm{Ev}}\right)$ and $G_{\mathrm{vh}}\left(\mathrm{PTP}_{\mathrm{Gvh}}\right)$ are determined and plotted in the stress-strain field along with PTP $_{\mathrm{v}}$ and $q_{\text {max }}$ as shown in Figs. 23(a) and (b). It is seen that $\mathrm{PTP}_{\mathrm{Ev}}$ and $\mathrm{PTP}_{\mathrm{Gvh}}$ appear first and following that PTP $_{\mathrm{v}}$ and $q_{\mathrm{max}}$ are obtained. This is similar to what was observed in Series 1. Also, $\mathrm{PTP}_{\mathrm{Ev}}$ and $\mathrm{PTP}_{\mathrm{Gvh}}$ are obtained at almost the same axial strain levels of $0.3 \%$ to $0.4 \%$, irrespective of the curing stress, period and confining stress. This again indicates that the point where the degradation of cementation bond starts is the level of axial deformation due to the relative displacement of particles, which causes the change in the phases of $E_{\mathrm{v}}$ and $G_{\mathrm{vh}}$, as explained earlier in Series 1 .

\section{CONCLUSIONS}

- Toyoura sand mixed with only $4.13 \%$ of cement by weight has a much higher strength than fresh sand alone, increased by a factor of approximately 3.5 times after 90 days.

- Curing stress increases the peak strength, the Young's modulus and the shear modulus irrespective of the curing period. 


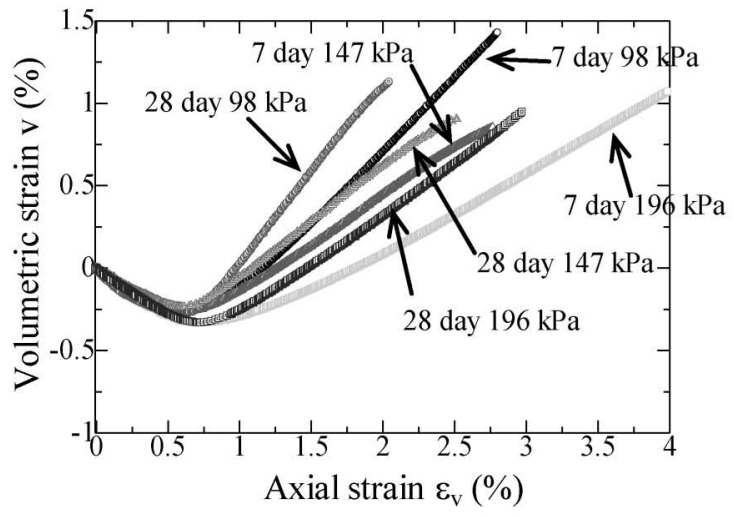

(a)

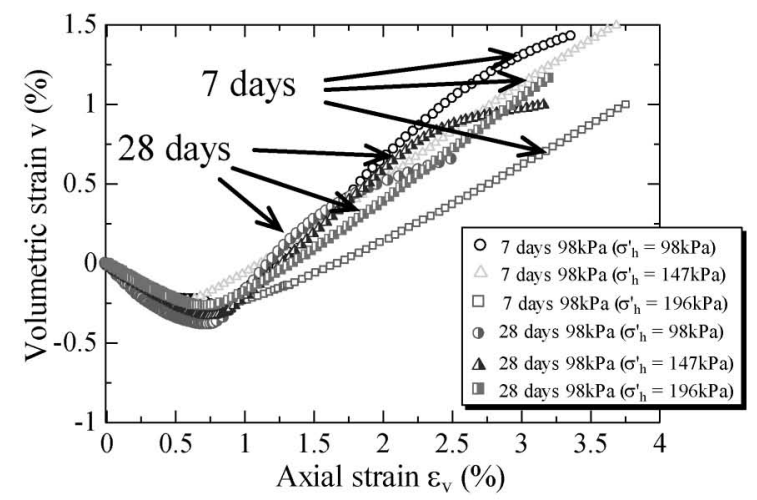

(b)

Fig. 20. Volume change curves for specimens (a) cured in the absence of stress, (b) cured under stress (Series 2)

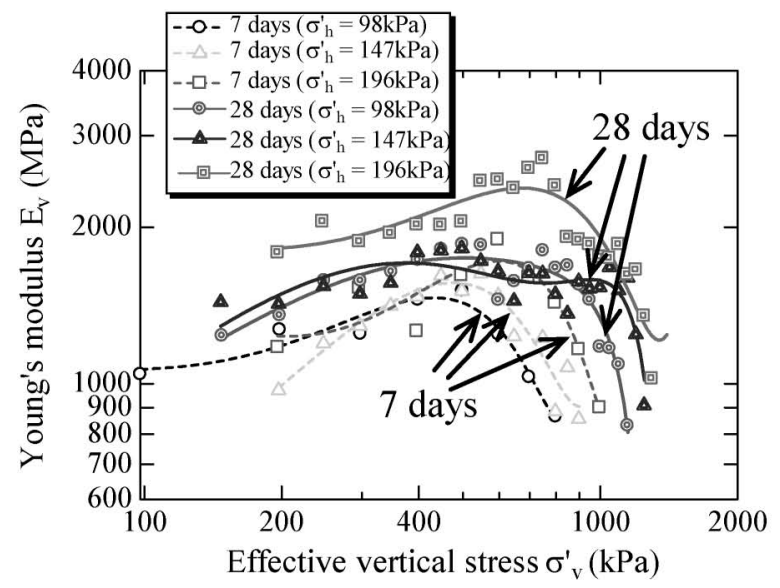

(a)

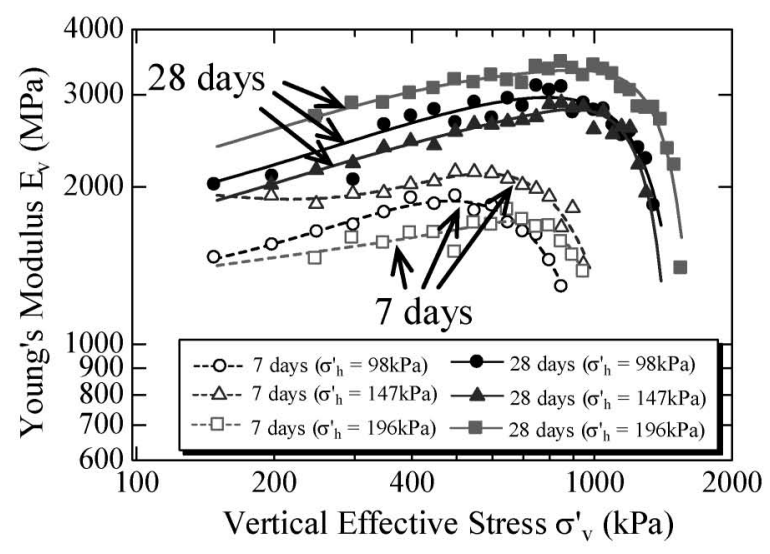

(b)

Fig. 21. Change of Young's modulus for specimens (a) cured without stress, (b) cured under stress (Series 2)

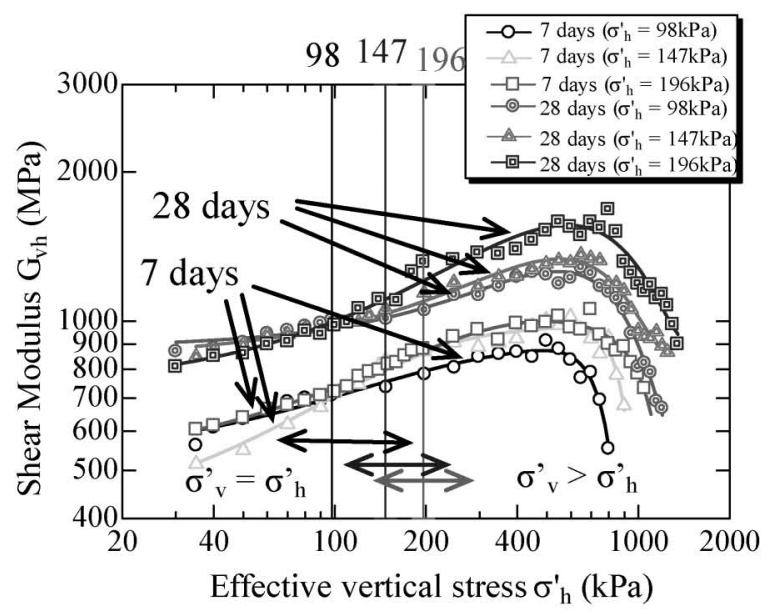

(a)

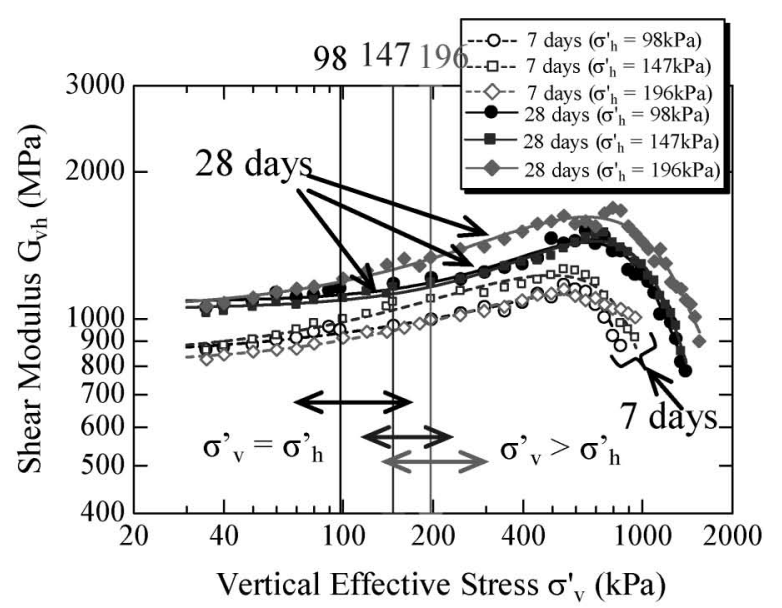

(b)

Fig. 22. Change of shear modulus for specimens (a) cured without stress, (b) cured under stress (Series 2) 


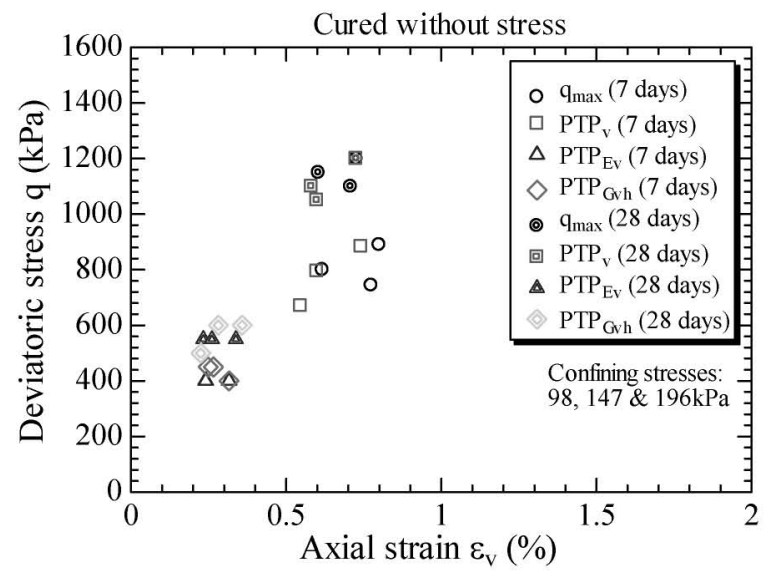

(a)

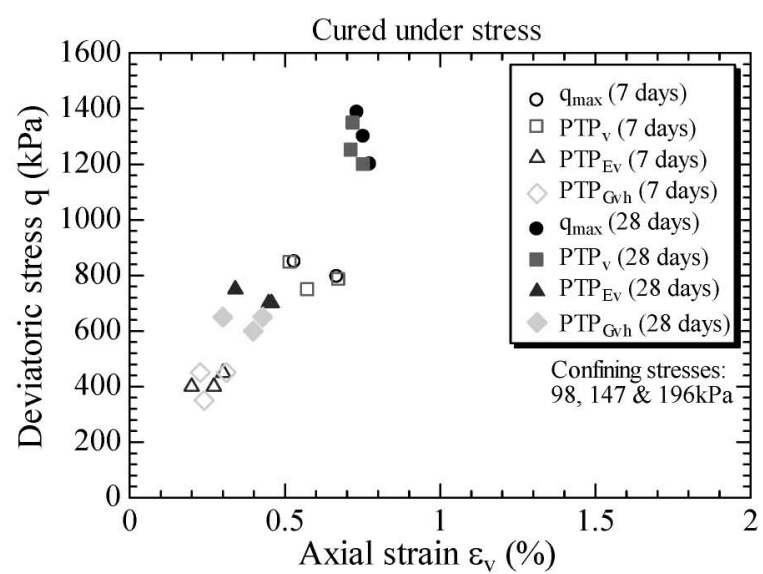

(b)

Fig. 23. Phase Transformation Points (PTP) for specimens (a) cured in the absence of stress, (b) cured under stress (Series 2)

- Longer curing periods result in increases of the stiffness, peak strength, the Young's modulus and the shear modulus, irrespective of the availability of curing stress.

- $G_{\mathrm{vh}}$ increases during the application of curing stress as the void ratio decreases. It is also noted to increase with time even when the void ratio remains constant.

- The curing stress and period both increase the range of vertical effective stress $\sigma_{\mathrm{v}}^{\prime}$ where the phase transformation occurs for $E_{\mathrm{v}}$ and $G_{\mathrm{vh}}$.

- The phase transformation of $E_{\mathrm{v}}$ and $G_{\mathrm{vh}}$ occurs at almost the same level of axial strain, at $0.3 \%$ to $0.4 \%$. This might be due to the start of the degradation of the cementation bond at that level of axial deformation due to the relative displacement of particles.

\section{ACKNOWLEDGEMENTS}

This study was performed at the Geosphere Research Institute of Saitama University (GRIS), Japan. The help of the staff and colleagues of Geotechnical Laboratory are greatly appreciated. The first author would like to acknowledge the financial support of the Asian Development Bank-Japan Scholarship Program (ADB-JSP) and express his appreciation.

\section{REFERENCES}

1) Chaudhary, S. K., Kuwano, J. and Hayano, Y. (2004): Measurement of quasi-elastic stiffness parameters of dense Toyoura sand in hollow cylinder apparatus and triaxial apparatus with bender elements, Geotechnical Testing Journal, 27(1), 23-35.

2) Consoli, N. C., Rotta, G. V., and Prietto, P. D. M. (2000): Influence of curing under stress on the triaxial response of cemented soils, Geotechnique, 50(1), 99-105.
3) Consoli, N. C., Foppa, D., Festugato, L. and Heineck, K. S. (2007): Key parameters for strength control of artificially cemented soils, J. Geotech. Geoenviron. Eng., 133(2), 197-205.

4) Dyvik, R. and Madshus, C. (1985): Lab measurements of $G_{\max }$ using bender elements, Proceedings of Advances in the Art of Testing Soils under Cyclic Conditions, (ed. by V. Khosla), ASCE Annual Convention, Detroit, Michigan, 186-196.

5) Hardin, B. O. and Blandford, G. E. (1989): Elasticity of particulate materials, Journal of Geotechnical Engineering, ASCE, 115(6), 788-805.

6) Kongsukprasert, L., Tatsuoka, F. and Tateyama, M. (2005): Several factors affecting the strength and deformation characteristics of cement-mixed gravel, Soils and Foundations, 45(3), 107-124.

7) Kongsukprasert, L., Tatsuoka, F. and Tateyama, M. (2007): Effects of curing period and stress conditions on the strength and deformation characteristics of cement-mixed soil, Soils and Foundations, 47(3), 577-596.

8) Kuwano, J., Chaudhary, S. K. and Ohba, H. (2005): Change in multiple yield surfaces of dense Toyoura sand with shearing in a $p^{\prime}$ constant plane, Geomechanics: Testing, Modeling, and Simulation, Geotechnical Special Publication, 143, ASCE, 319-340.

9) Kuwano, J. and Tay, W. B. (2007): Effects of curing time and stress on the strength and deformation characteristics of cement-mixed sand, Soil Stress-Strain Behavior: Measurement, Modeling and Analysis (eds. by Ling, H. I., Callisto, L., Leshchinsky, D. and Koseki, J.), Springer, 413-418.

10) Ohba, H., Chaudhary, S. K., Matsushima, T., Kuwano, J. and Takahashi, A. (2001): DEM simulation of anisotropic shear behavior of granular material, Proc. 36th Japan National Conference on Geotechnical Engineering, 507-508 (in Japanese).

11) Taguchi, T., Suzuki, M., Yamamoto, T., Fujino, H., Okabayashi, S. and Fujimoto, T. (2002): Influence of consolidation stress history on unconfined compressive strength of cement-stabilized soil, Technical Report, Department of Engineering, Yamaguchi University, 52(2), 87-92 (in Japanese).

12) Tay, W. B. (2005): Effect of curing time and stress on the strength and deformation characteristics of cement-mixed sand, Master's Dissertation, Tokyo Institute of Technology, Japan.

13) Viggiani, G. and Atkinsion, J. H. (1995): The interpretation of bender element tests, Geotechnique, 45(1), 149-155. 